\title{
Treatment Management in a Patient with Giant Ruptured Internal Iliac Artery Aneurysm
}

\section{Mehmet Işsk, ๑ Ömer Tanyeli}

Necmettin Erbakan University Meram Faculty of Medicine, Depatment of Cardiovascular Surgery, Konya, Turkey

\begin{abstract}
Occurrences of internal iliac artery aneurysms are rare cases. It is mostly seen in older men and is associated with other aortic aneurysms. Aneurysms can cause high mortality, such as rupture, if not diagnosed and treated early. In this study, we present an 88-year-old male patient with disrupted general status, who had comorbidities and a ruptured internal iliac artery aneurysm of about $10 \mathrm{~cm}$. Because the aneurysm was too large, it could not be closed by using only coil embolization. It is unusual for thrombosis
\end{abstract}

\section{Introduction}

Internal iliac artery aneurysms are mostly associated with the other aortic aneurysms. Of all iliac artery aneurysms, $70 \%$ are originated from the common iliac to be achieved by adding cyanoacrylate. Cyanoacrylate is currently used for the ablation of venous insufficiency. This case was interesting because cyanoacrylate was used to achieve thrombosis of the arterial system. In this study, our aim was to share the successful percutaneous treatment of the giant aneurysm with triple coil embolization, cyanoacrylate and covered stent placement.

Keywords: Aneurysm, internal iliac artery, endovascular procedure

artery, 20\% from the internal iliac arteries, and 10\% from the external iliac arteries ${ }^{(1)}$. Iliac artery aneurysms are more commonly found in elderly men than in women. This ratio has been reported to be between 5/1 and 25/1 (occurrences found at the ratio of men to women) in different studies ${ }^{(2)}$.

Address for Correspondence: Mehmet Işık, Necmettin Erbakan University Meram Faculty of Medicine, Depatment of Cardiovascular Surgery, Konya, Turkey

Phone: +90 5335507549 e-mail: drmisik@hotmail.com ORCID: orcid.org/0000-0002-2154-7473

Received: 23.03.2020 Accepted: 12.05 .2020

Cite this article as: Iş̧1k M, Tanyeli Ö. Treatment Management in a Patient with Giant Ruptured Internal Iliac Artery Aneurysm. EJCM 2020;8(2):103-106.

DOI: $10.32596 /$ ejcm.galenos.2020.03.015

Presented in: This study was presented as an oral presentation at the $15^{\text {th }}$ International Congress of Cardiology and Cardiovascular Surgery (27-30 March 2019). 
The main complaints include abdominal pain, claudication, embolism and compression related symptoms. Abdominal ultrasonography, computed tomography, magnetic resonance imaging, and other angiographic imaging modalities are used for the diagnosis. In treatment, surgical and endovascular methods are alternative to each other.

\section{Case Report}

An 88-year-old male patient presented with the complaints of poor general condition and abdominal pain to an outer center. He was referred to our clinic with the diagnosis of ruptured right iliac artery aneurysm after investigations were carried out in the center. His medical history revealed a history of right cholecystectomy, hypertension, chronic obstructive pulmonary disease, 50 pack/year of smoking, peripheral artery disease for 15 years, and coronary artery bypass surgery in 2009 . In the physical examination, his general health status was moderate-to-poor and there were agitation, limited orientation-cooperation, and a palpable mass in the right lower quadrant, and rebound-defense positivity. Both feet were cold, but there was no ischemia finding. Only right tibialis posterior and dorsalis pedis could not be palpated, whereas the other pulses were palpated.

Computed tomography angiography revealed an aneurysm reaching to $10 \mathrm{~cm}$ diameter in the right internal iliac artery with intra-and extra peritoneal free fluid (Figure 1). The patient's general status was poor. The urea value was $63 \mathrm{mg} / \mathrm{dL}$, creatinine was $1.7 \mathrm{mg} / \mathrm{dL}$, the PT (INR) value was found as 2.5 , and hemoglobin was found to be $7.05 \mathrm{~g} / \mathrm{dL}$. We decided to perform an emergency endovascular procedure. An image was acquired by accessing with left femoral catheterization under general anesthesia and extravasation was observed to continue (Figure 2A). The right iliac artery was reached by crossing the iliac bifurcation left to the right and 16 coil embolizations $(7 \times 2.3 \mathrm{~mm})$ were made into the right internal iliac artery, but only half of the aneurysm could be filled. Thereupon, 2 cc cyanoacrylate was poured onto the coil embolizations (Figure 2B). Subsequently, the inside of the aneurysm was completely thrombosed. Next, a covered stent $(13.5 \times 10 \mathrm{~cm})$ was inserted between the common iliac artery and external iliac artery via the right femoral artery, so as to close ostium of the internal iliac artery. Proximal and distal of the stent were ballooned. In the control exposures, there were no extravasation and endoleak. The operation was terminated with the decision of later intervention on the left iliac artery (Figure 3). General status of the patient was resolved in the intensive care unit without a drop-in hemoglobin. He was taken to the ward on the day $4^{\text {th }}$ and later transferred to the department of chest diseases due to respiratory problems. However, later, the patient was intubated due to respiratory problem. During her follow-up, kidney failure and pneumonia developed. Urea value increased to 123 $\mathrm{mg} / \mathrm{dL}$, creatinine to $6.7 \mathrm{mg} / \mathrm{dL}$, hemoglobin to $9.6 \mathrm{~g} / \mathrm{dL}$, C-reactive protein to $220 \mathrm{mg} / \mathrm{L}$ and procalcitonin to $15 \mu \mathrm{g} /$ $\mathrm{mL}$. The patient was performed hemodialysis treatment. On the $9^{\text {th }}$ postoperative day, despite the maximum medical treatment, the patient died.

\section{Discussion}

Aneurysms may develop in any region of the arterial system. The known causes of aneurysms include atherosclerosis, infections, iatrogenic, traumatic, arthritis,

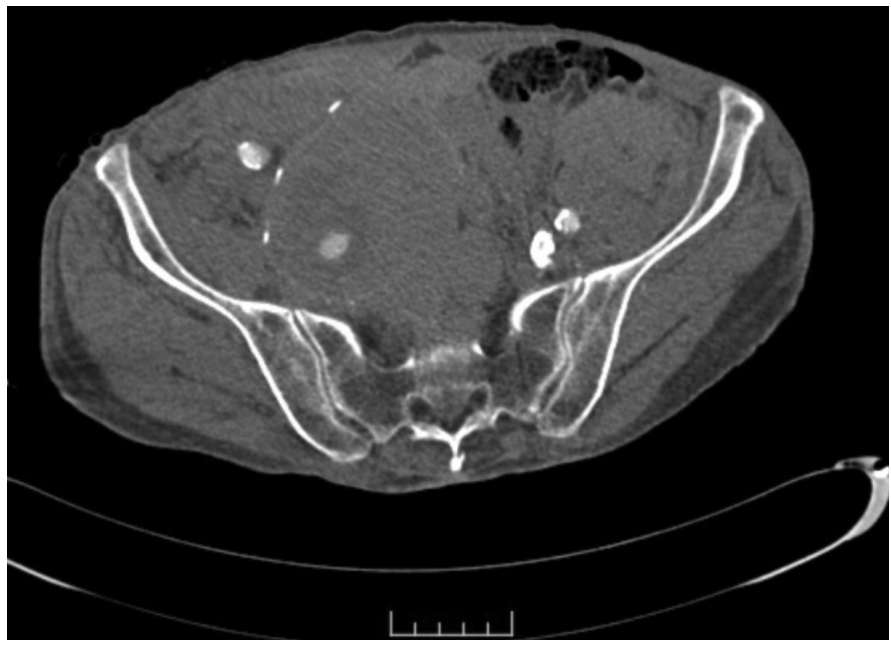

Figure 1. Preoperative CT view of aneurysm CT: Computed tomography 


Ease Report
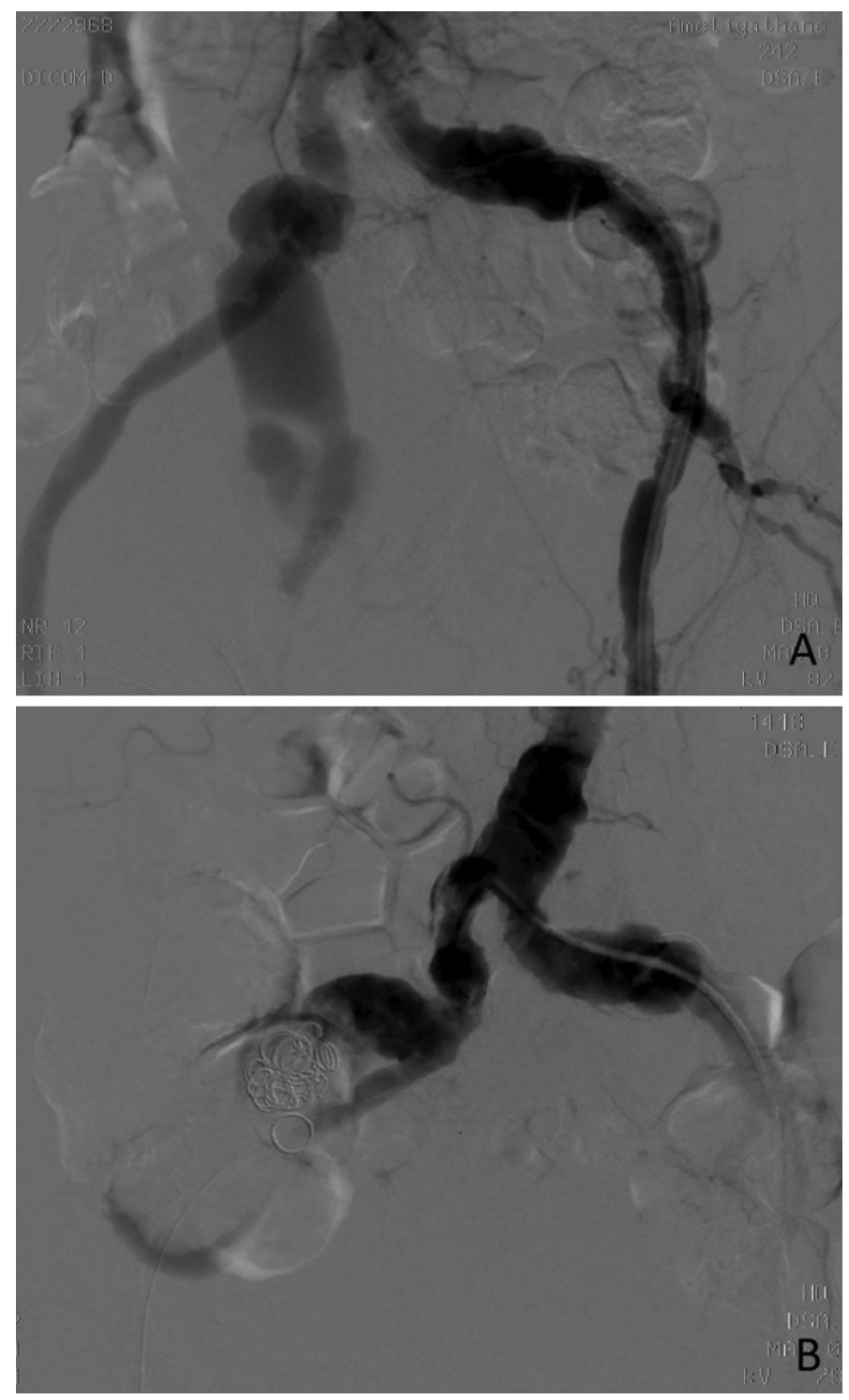

Figure 2. A) Imaging of the aneurysm with left femoral catheterization. B) Image after 1 cc cyanoacrylate

connective tissue disorders, and congenital diseases. An increase in the aneurysm diameter increases the rupture risk factor.

Intervention is recommended in patients with an iliac artery diameter over $3.5 \mathrm{~cm}$. The mortality rate of emergency surgery due to a rupture is between $33 \%$ and $55 \%$ and the rate of elective surgery varies from $2 \%$ to $11 \%{ }^{(2)}$. Therefore, early diagnosis and elective intervention before rupture development are of paramount importance.

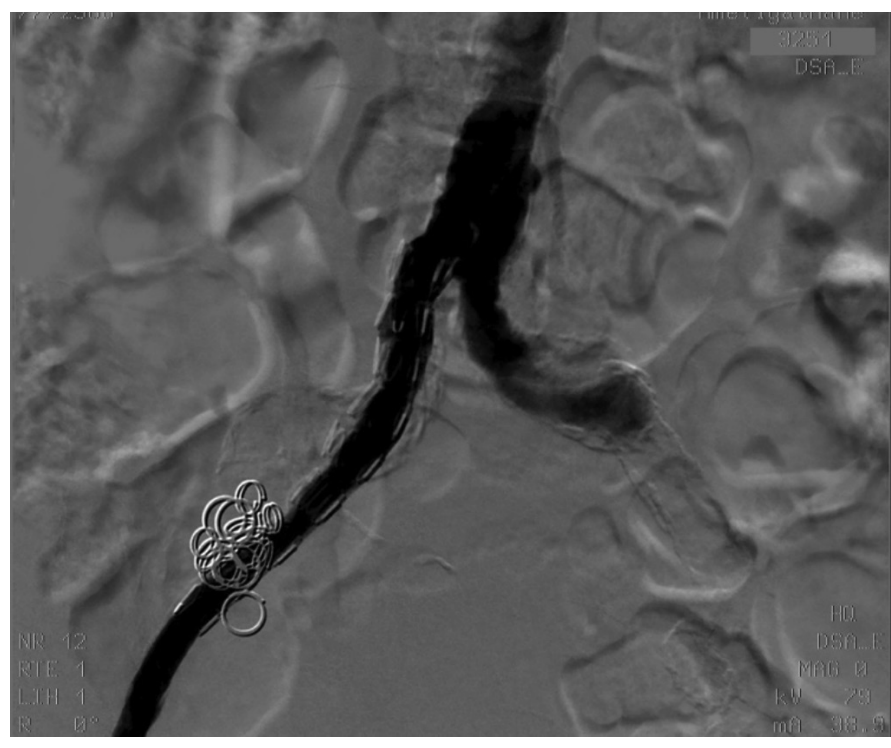

Figure 3. Last image acquired after the application of covered stent and balloon

Ligations, graft interposition following aneurysmectomy, or endoaneurysmorrhaphy are used as surgical methods in the management of internal iliac artery aneurysms. Although there is a satisfactory technical success, surgical intervention has quite a number of complications. Among these are hemorrhage, infections, urethral injury, distal embolism, and ischemia in the lower extremities.

Recently, with the advancements in stenting technology and operational experience, endovascular procedures have become a great alternative to surgery. Endovascular aortic replacement shortens the hospitalization duration and length of stay in the intensive care unit, including the patients with ruptured aneurysms, and seems superior over surgery in terms of short and middle term outcomes in the treatment of iliac artery aneurysms ${ }^{(3)}$.

It has been reported that endovascular repair methods reduce the length of hospital stay and decrease the amount of bleeding at the time of surgery, and the mid-term results are similar to those of surgery in patients with isolated iliac aneurysm ${ }^{(4)}$.

Although 16 coils of embolizant were used in the patient with comorbid conditions, the aneurysm could not be closed. It was not reasonable to insert stent without 
thrombosing the aneurysms of such size. This is because the stent might be displaced and could lead to endoleak during the progression. Therefore, cyanoacrylate was added on the coil embolizations and entire aneurysm was thrombosed.

Nowadays, cyanoacrylate is commonly used for ablation in the treatment of venous insufficiency ${ }^{(5,6)}$. However, it is not common for its use to achieve thrombosis in the arterial system. Making thrombosis with glue alone was another alternative. However, we thought that there was a chance that the glue might be extravasated from surface of the ruptured aneurysm. We did not know how the cyanoacrylate would react after leaking to the abdomen. First, we performed coil embolization and closed the segment somewhat in order to avoid extravasation of cyanoacrylate. Next, glue was added on it and total thrombosis was achieved. A covered stent was then inserted on the segment which we thought would provide stabilization.

There was no postoperative allergic reaction and the extravasation was successfully controlled. Further studies are needed for the use of cyanoacrylate in the arterial system for the purpose of glue.

\section{Ethics}

Informed Consent: Article software consent was obtained from the patient and his/her relatives.
Peer-review: Internally and externally peer-reviewed.

\section{Authorship Contributions}

Surgical and Medical Practices: M.I., Ö.T., Concept: M.I., Ö.T., Design: M.I., Ö.T., Data Collection or Processing: M.I., Ö.T., Analysis or Interpretation: M.I., Ö.T., Literature Search: M.I., Writing: M.I.

Conflict of Interest: There is no conflict of interest.

Financial Disclosure: Financial support was not received.

\section{References}

1. Minato N, Itoh T, Natsuaki M, Nakayama Y, Yamamoto H. Isolated iliac artery aneurysm and its management. Cardiovasc Surg 1994;2:489-94.

2. Richardson JW, Greenfield LJ. Natural history and management of iliac aneurysms. J Vasc Surg 1988;8:165-71.

3. Özbudak E, Kanko M, Yavuz Ş, Gümüştaş S, Arıkan Ahmet A, Çiftçi E, et al. Isolated iliac artery aneurysms: a comparison of surgical method and endovascular approaches. Turk Gogus Kalp Dama 2013;21:317-24.

4. Ferreira J, Canedo A, Brandao D, Maia M, Braga S, Chaparro M, et al Isolated iliac artery aneurysms: six-year experience. Interact Cardiovasc Thorac Surg 2010;10:245-8.

5. Hassanian A, Aherne TM, Greene G, Boyle E, Egan B, Tierney S, et al. A systematic review and meta-analysis of comparative studies comparing non thermal versus thermal endovenous ablation in superficial venous incompetence. J Vasc Surg Venous Lymphat Disord 2019;7:902-13.

6. Yasim A, Eroglu E, Bozoglan O, Mese B, Acipayam M, Kara H. A new nontumescent endovenous ablation method for varicose vein treatment: Early results of N-butyl cyanoacrylate (VariClose $®)$. Phlebology 2017;32:194-9. 